\title{
Papaverine hydrochloride containing nanostructured lyotropic liquid crystal formulation as a potential drug delivery system for the treatment of erectile dysfunction
}

This article was published in the following Dove Press journal:

Drug Design, Development and Therapy

\author{
Szilvia Berkó' \\ Stella Zsikó' \\ Gábor Deák ${ }^{2}$ \\ Attila Gácsi' \\ Anita Kovács' \\ Mária Budai-Szűcs' \\ László Pajor ${ }^{2}$ \\ Zoltán Bajory ${ }^{2}$ \\ Erzsébet Csányi' \\ 'Institute of Pharmaceutical \\ Technology and Regulatory Affairs, \\ University of Szeged, Szeged, Hungary; \\ ${ }^{2}$ Department of Urology, University \\ of Szeged, Szeged, Hungary
}

Purpose: Papaverine hydrochloride $(\mathrm{PaHCl})$ is an old, well-known drug with spasmolytic activity but it has therapeutic effect in erectile dysfunction, too. As an intracavernous injection, it is not used in urologic clinics today because the side effects of the injection are pain, scarring or priapism. Our aim was to develop and test a topical semi-solid preparation containing $\mathrm{PaHCl}$ that would provide an alternative administration option by eliminating the undesirable side effects of the injection.

Materials and methods: Lyotropic liquid crystal (LLC) systems were formulated as a semi-solid preparation with different concentrations of $\mathrm{PaHCl}$. The characterization of the LLC structure was performed by polarization microscopy using a Leica image analyzer and rheological measurements. The drug diffusion and penetration tests were performed with in vitro synthetic membrane and an ex vivo human epidermis, using Franz diffusion cell to test the skin penetration of $\mathrm{PaHCl}$. Human skin was investigated by Raman microscope to visualize the Active Pharmaceutical Ingredient (API) in different skin layers.

Results: The results of diffusion and penetration showed reverse concentration dependency. The in vitro and ex vivo studies correlated with each other and the results of Raman microscopy. The LLC structure influenced the penetration results, the lower viscosity and lamellar structure increased penetration through the skin.

Conclusion: Based on our results, a $\mathrm{PaHCl}$ containing topically used LLC formulation may be a suitable and effective alternative to the injectable formulation.

Keywords: nanocarrier, dermal penetration, impotence, Raman microscopy

\section{Introduction}

Erectile dysfunction (ED) is described as the persistent disability to attain and sustain an erection sufficient to permit satisfactory sexual performance. ${ }^{1,2} \mathrm{ED}$ is a common disease. There are about 100 million men having ED worldwide. According to surveys, $40 \%$ of men over the age of 40 have at least a slight degree of ED, which increases with progressing age. ${ }^{3}$ Epidemiological data have proved a high prevalence and incidence of ED in all countries. The real prevalence is hard to find out because a lot of people are ashamed of the problem. Because of this, up to $70 \%$ of men with ED are not treated. ED may change physical and psychosocial health, and may have an important influence on the quality of life of patients and their partners, too. ${ }^{4}$ There is evidence that ED can be an early sign of coronary artery and peripheral vascular disease. ${ }^{5}$
Correspondence: Erzsébet Csányi Institute of Pharmaceutical Technology and Regulatory Affairs, University of Szeged, Eötvös u. 6, Szeged 6720, Hungary

Tel +3662545573

Fax+3662545 571

Email csanyi@pharm.u-szeged.hu (c) (1) (-) 2018 Berkó et al. This work is published and licensed by Dove Medical Press Limited. The full terms of this license are available at https://www.dovepress.com/terms.php (c) hereby accept the Terms. Non-commercial uses of the work are permitted without any further permission from Dove Medical Press Limited, provided the work is properly attributed. For permission for commercial use of this work, please see paragraphs 4.2 and 5 of our Terms (https://www.dovepress.com/terms.php). 
The current therapeutic options for ED are the following. ${ }^{6}$ In first-line treatment, oral phosphodiesterase-5 (PDE5) inhibitors are used. Classical drugs are sildenafil, vardenafil, and tadalafil, while the newest one is avanafil. ${ }^{7,8}$ These have many unwanted side effects, such as headache, nausea, dizziness. In second-line treatment, intracavernosal or intraurethral alprostadil therapy is used in patients who do not respond or are contraindicated for PDE5 inhibitors. ${ }^{9}$ Both methods are extremely uncomfortable for the patient; they are painful and involve significant financial difficulties as well as undesirable side effects, such as penis pain, hemorrhages, and burning in the urethra. To increase the small number of therapeutic options and to avoid unpleasant side effects, more and more research is directed at the transdermal entry gate. ${ }^{10-12}$

During topical treatment, if the active ingredient is delivered to the deeper layers of the skin, it is possible to penetrate into the corpus cavernosum by exerting the effect through the underlying vessels. The topical administration of drugs has many benefits compared to oral or injection applications. In the case of topical application, Active Pharmaceutical Ingredients (APIs) avoid the first pass effect and better bioavailability becomes possible. There is no plasma peak concentration, so the incidence of side effects may be reduced. Moreover, topical use enables continuous drug delivery and patient compliance can also be improved with the Drug delivery systems of the preparation. ${ }^{13-19}$ In a 2015 survey, $153 \mathrm{ED}$ patients were asked to rank the different therapies from most to least desirable. The survey shows that there is a need for topical therapy because $53 \%$ of the people chose this application method first. ${ }^{20}$

Lyotropic liquid crystals (LLCs) have a number of beneficial properties from the point of view of pharmaceutical technology. LLCs are usually formed of water, one or two tensides, and oil in a specified concentration and temperature range. They are suitable carrier systems for hydrophilic, lipophilic or amphiphilic drugs. They are extremely stable systems thermodynamically and can be maintained for a long time without the separation of the phases, so their structure is retained for a long time without structural changes. They also promote the penetration of the active substances through the skin, due to the low surface tension at the water-oil interface. ${ }^{21,22}$ Their use through the skin is especially advantageous, given the the concentration ratio of the components of LLC; the structure of the double lipid layer of the stratum corneum presents a similar lamellar structure and therefore their application can improve the penetration of the active ingredients.

Papaverine hydrochloride ( $\mathrm{PaHCl})$ is an old, well-known opium alkaloid. It is primarily used with spasmolytic indications in therapy. In 1982, a French surgeon, Ronald Virág discovered in Paris that $\mathrm{PaHCl}$ can be used as an intracavernosal injection. ${ }^{23}$ The injection with $\mathrm{PaHCl}$ was used for a long time as a second-line treatment but is not relevant today because of more discomfort or side effects for the patient.

A new drug delivery system with an old, well-known drug can be a promising combination to achieve the expected effect and improve the side effects profile. The aim of the present study was to prepare $\mathrm{PaHCl}$ containing LLC formulations ( $\mathrm{PaHCl}-\mathrm{LLC})$ with improved drug release properties (for the potential treatment of ED) and to characterize the formulation by means of techniques such as polarization microscopy and rheology measurement, and to model the skin penetration by a vertical Franz diffusion cell system and Raman microscopy. ${ }^{24,25}$

\section{Materials and methods Materials}

The active ingredient, $\mathrm{PaHCl}$ was obtained from Hungaropharma Ltd (Budapest, Hungary). The LLC was composed of two nonionic surfactants: Kolliphor RH40 (polyoxyl 40 hydrogenated castor oil The United States Pharmacopeia- National Formulary [USP/NF]) was supplied by BASF SE Chemtrade $\mathrm{GmbH}$ (Ludwigshafen, Germany), and Tween 80 (polyoxyethylene [20] sorbitan oleate) and an oil component, isopropyl myristate, were purchased from Merck (Budapest, Hungary).

\section{Preparation of the samples}

$\mathrm{PaHCl}$ was used in three different concentrations, 2.5, 3 and $4 \mathrm{w} / \mathrm{w} \%$ in the LLC systems. Drug-loaded LLCs were prepared with the following procedure. $\mathrm{PaHCl}$ was dissolved in the hot water phase. Kolliphor RH 40 was melted, mixed with isopropyl myristate and Tween 80 , and finally the aqueous phase was added in small portions to this mixture during gentle stirring to form the liquid crystals. A blank formulation were also prepared without $\mathrm{PaHCl}$ with the same procedure.

\section{Polarization microscopy}

To verify the special structure of the LLC composition, a polarization microscope was used (Leica Q500MC image processing and analyzing system, Leica Microsystems Cambridge Ltd., Cambridge, United Kingdom) with crossed polarizers at room temperature. The magnification was $200 \times$.

\section{Rheological investigations}

Frequency-dependent oscillatory rheological measurements were performed with a Physica MCR101 rheometer to verify the structure of LLC systems and to differentiate the structure of compositions containing different concentrations of $\mathrm{PaHCl}$. The storage $\left(\mathrm{G}^{\prime}\right)$ and loss $\left(\mathrm{G}^{\prime \prime}\right)$ moduli were presented 
in the function of the change of the frequency $(0.01-100 \mathrm{~Hz})$ within the linear viscoelastic range. The measurements were carried out at $32^{\circ} \mathrm{C}$.

\section{Drug diffusion and penetration studies}

Vertical Franz diffusion cell (Hanson Microette TM Topical \& Transdermal Diffusion Cell System, Hanson Research Corporation, Chatsworth, CA USA) was used to model the drug liberation from the LLCs and diffusion and penetration through in vitro synthetic membrane and ex vivo human heat separated epidermis. Excised human skin was obtained from a Caucasian female patient by routine plastic surgery procedure in the Department of Dermatology and Allergology, University of Szeged. The ex vivo skin penetration test does not need ethical permission, and patient's consent according to the Act CLIV of 1997 on health, Section 210/A in Hungary. The local ethical committee (Ethical Committee of the University of Szeged, Albert Szent-Györgyi Clinical Center) was informed about the ex vivo skin penetration studies (Human Investigation Review Board license number: 83/2008).

In the case of in vitro studies, $0.3 \mathrm{~g}$ of sample was placed as a donor phase on the synthetic membrane filter (Porafil membrane filter, cellulose acetate, pore diameter: $0.45 \mu \mathrm{m}$, Macherey-Nagel GmbH \& Co. KG, Düren, Germany). In the case of ex vivo studies, heat-separated human epidermis was used as the membrane. The human skin was obtained from plastic surgery. As an acceptor phase, thermostated phosphate buffer (PBS pH 7.4 \pm 0.15 ) was used at $37^{\circ} \mathrm{C} \pm 0.5^{\circ} \mathrm{C}$. Membrane diffusion and skin penetration experiments lasted 6 (in vitro) and 24 hours (ex vivo). The concentration of the drug was measured spectrophotometrically with a Thermo Scientific Evolution 201 spectrometer with Thermo Insight v1.4.40 software package (Thermo Fisher Scientific, Waltham, MA, USA) at a wavelength of $250 \mathrm{~nm}$.

\section{Treatment of human full thickness skin, tissue preparation and investigation with Raman microscopy}

Human subcutaneous fat free skin (epidermis and dermis) was used for the measurements. Approximately $1 \mathrm{~cm}^{2}$ of the skin surface was treated with the compositions for 6 hours at $25^{\circ} \mathrm{C}$ and relative humidity $50 \%$. The treated skins were frozen and sectioned ( $10 \mu \mathrm{m}$ thick cross-sections) onto aluminum-coated slides using a Leica CM1950 cryostat (Leica Biosystems GmbH, Wetzlar, Germany). Before sectioning the skin samples, the LLCs were gently removed from the skin surface. Raman microscopic analyses were performed using a Thermo Scientific DXR Raman microscope (Thermo
Fisher Scientific, Waltham, MA, USA). The $780 \mathrm{~nm}$ wavelength laser light source was used, with a maximum power of $24 \mathrm{~mW}$. The microscopic lens used for the measurements had 50× magnification, and the aperture of the pinhole was $25 \mu \mathrm{m}$. In the case of chemical mapping, a $200 \times 1,800 \mu \mathrm{m}$ area was examined; the step size was $50 \mu \mathrm{m}$ vertically and horizontally. Overall, 205 spectra were recorded, for collecting each spectrum 16 scans were recorded, and the exposure time was 2 seconds. Instrument operation and the evaluation of measurements were done by the OMNIC for Dispersive Raman 8.2 software package (Thermo Fisher Scientific). The individual spectra of each component of LLC and $\mathrm{PaHCl}$ were used as a reference when comparing the treated vs untreated skin samples. For recording the individual spectra of the components and LLCs, a $532 \mathrm{~nm}$ laser source was used. For each spectrum 32 scans were recorded with 6 seconds exposure time. In the Raman microscope, the magnitude of optics was $10 \times$ with $25 \mu \mathrm{m}$ slit aperture.

\section{Statistical analysis}

The results were evaluated and analyzed statistically with the two-way analysis of variance test (Bonferroni's multiple comparison), using Prism for Windows software (GraphPad Software Inc., La Jolla, CA, USA). The data are the averages of the results of at least five experiments \pm standard deviation $(P<0.05, P<0.01$, and $P<0.001$ vs the control).

\section{Results and discussion \\ Characterization of LLC structure}

\section{Results of polarization microscopy}

The structures of the LLC samples were examined with a polarization microscope. The LLC structure shows a special pattern (Maltese crosses) in polarized light. Maltese crosses represent the lamellar LLC structure. ${ }^{26}$ The Maltese crosses were detected in the blank LLC and the compositions containing 2.5 and $3 \mathrm{w} / \mathrm{w} \%$ of $\mathrm{PaHCl}$. They were not detectable in the composition of $4 \mathrm{w} / \mathrm{w} \% \mathrm{PaHCl}$. We assume that the increasing amount of dissolved $\mathrm{PaHCl}$ could have caused phase transition of LLC. The maltese crosses represent the lamellar structure. There was no detectable maltese crosses when the concentration of $\mathrm{PaHCl}$ is 4 (Figure 1D). Missing of maltese crosses show the structural transformation (Figure 1).

\section{Results of rheological measurements}

The oscillation rheological measurements also justify the structural change (Figure 2). In the case of our LLC systems, the storage $\left(\mathrm{G}^{\prime}\right)$ and loss $\left(\mathrm{G}^{\prime \prime}\right)$ moduli increase with increasing concentration of $\mathrm{PaHCl}$. The higher values of storage and loss moduli, with a higher order of magnitude, suggest 

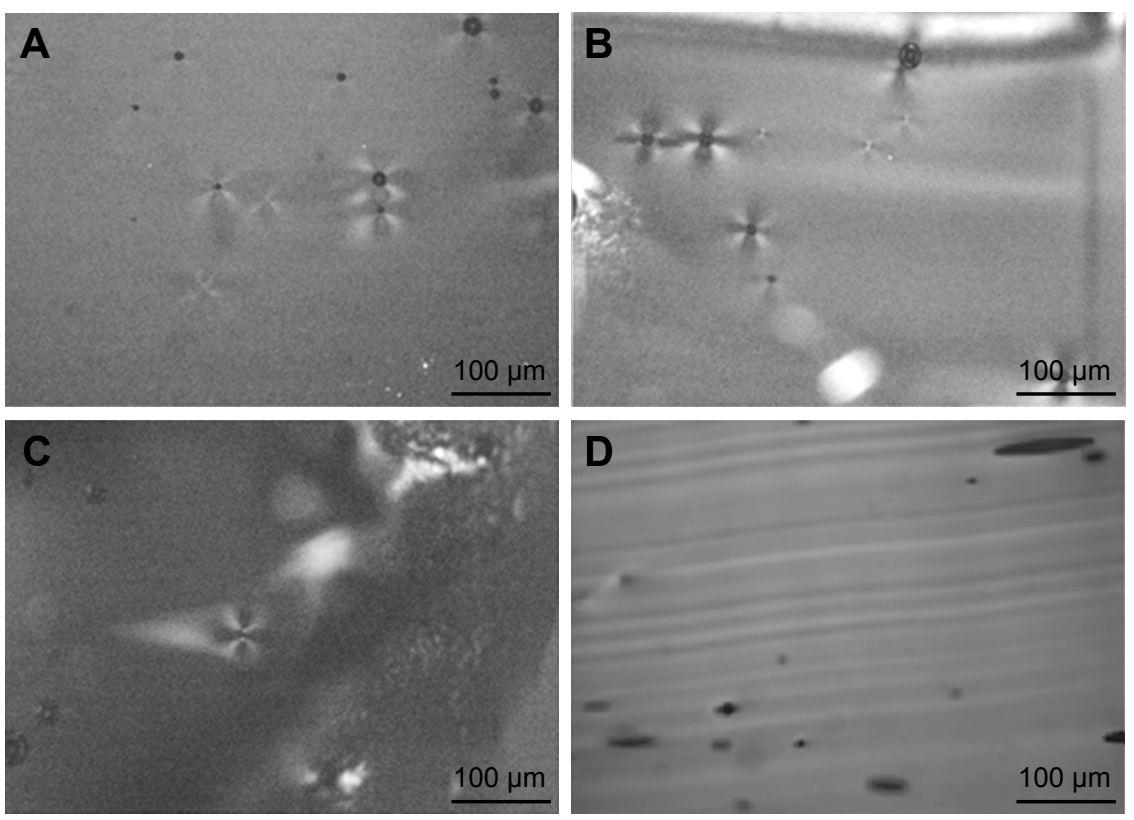

Figure I The polarization microscopic pictures of LLC with different $\mathrm{PaHCl}$ concentrations.

Notes: (A) Blank LLC; (B) 2.5 w/w\% PaHCl-LLC; (C) 3 w/w\% PaHCl-LLC; (D) 4 w/w\% PaHCl-LLC. Magnification 200x.

Abbreviations: $\mathrm{PaHCl}$, papaverine hydrochloride; LLC, lyotropic liquid crystal.

A

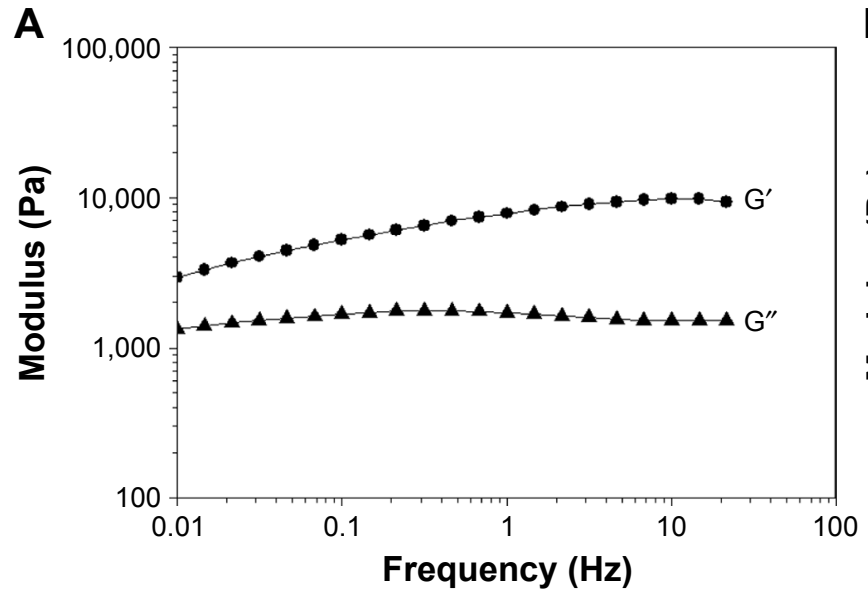

C

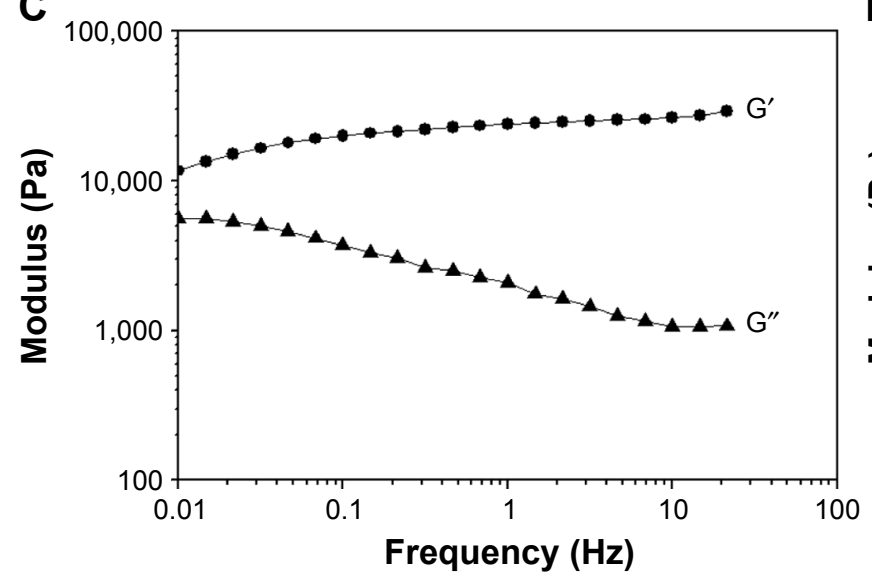

B

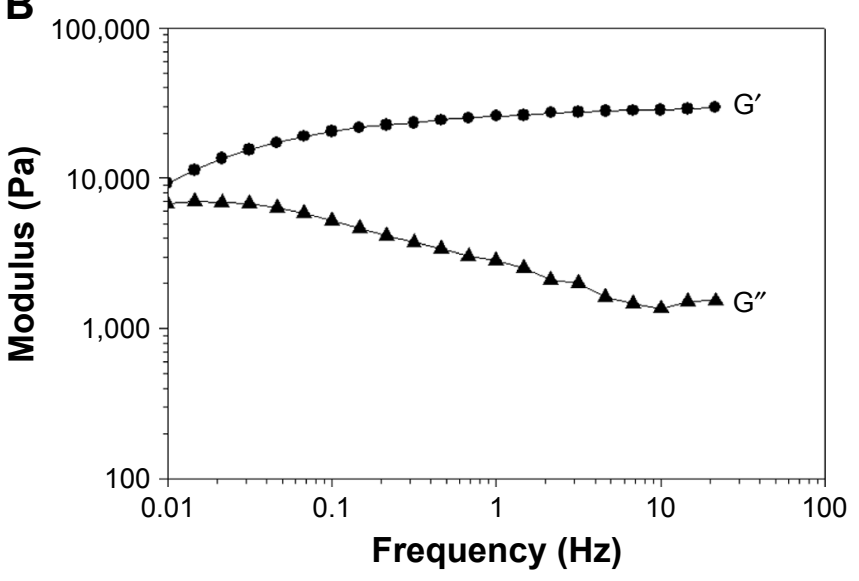

D

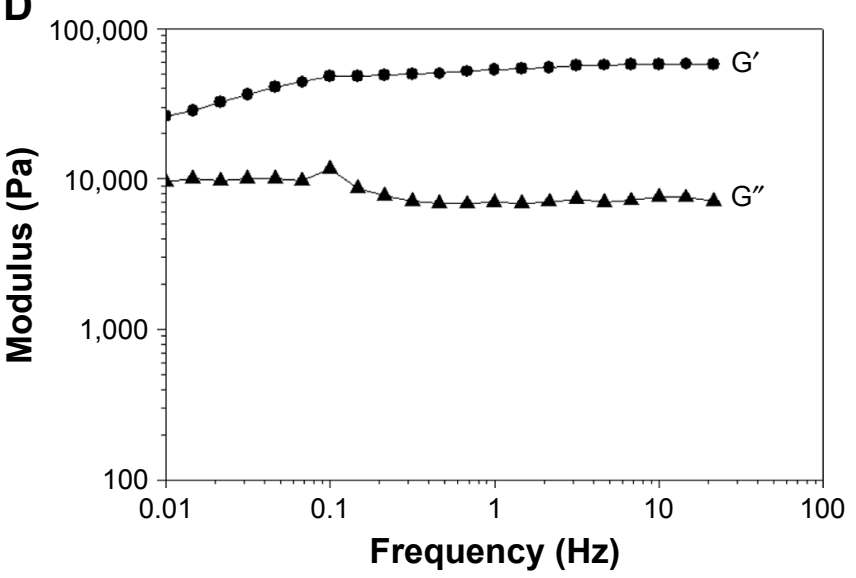

Figure 2 Oscillation rheological measurement.

Notes: (A) Blank LLC; (B) 2.5 w/w\% PaHCl-LLC; (C) 3 w/w\% PaHCl-LLC; (D) 4 w/w\% PaHCl-LLC. •G': storage modulus; $\mathbf{\Delta}$ G": loss modulus.

Abbreviations: $\mathrm{PaHCl}$, papaverine hydrochloride; LLC, lyotropic liquid crystal. 
that the LLC structure is intact after drug incorporation into the liquid crystal structure, altering the system's properties, such as viscosity. The cubic phase is more viscous than the corresponding hexagonal or lamellar phases according to the literature. ${ }^{27}$ The increasing viscosity of the system may inhibit the release of the active substance from the given system, and it was assumed that the lamellar structure transformed into a cubic structure after the drug concentration was increased.
The microscopic and rheological studies confirm that $\mathrm{PaHCl}$ used in higher concentrations in the LLC system resulted in structural changes, and predict lower diffusion and penetration results.

\section{Results of drug diffusion and penetration}

In vitro drug release through a synthetic membrane (Figure $3 \mathrm{~A}$ ) and ex vivo penetration through the human
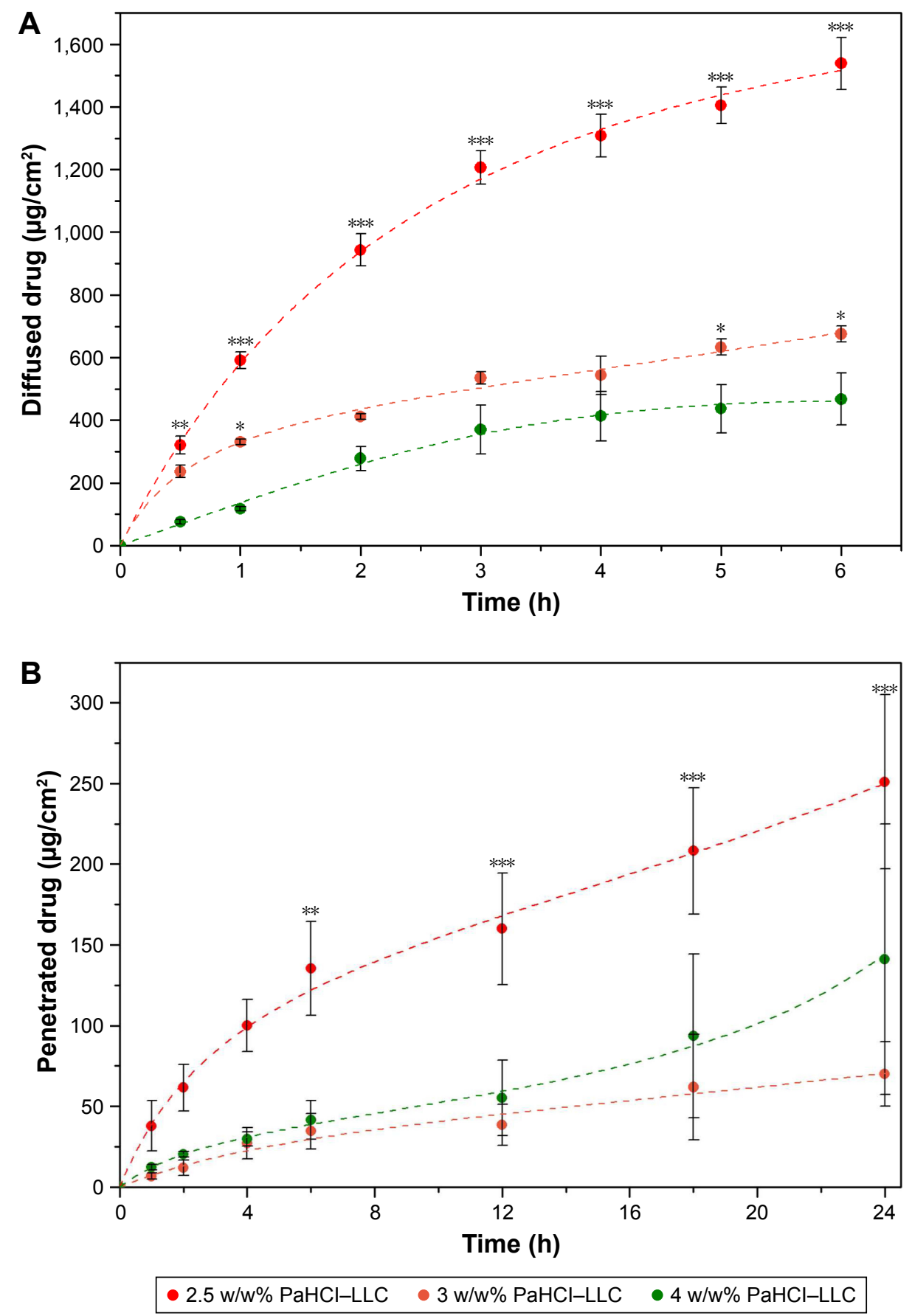

Figure 3 In vitro drug diffusion, $* p<0.05 * * p<0.0$ I *** $p<0.00$ I vs $4 \mathrm{w} / \mathrm{w} \% \mathrm{PaHCl}-\mathrm{LLC}(\mathbf{A})$ and ex vivo skin penetration, $* * p<0.0 \mathrm{I} * * * p<0.00 \mathrm{I}$ vs $3 \mathrm{w} / \mathrm{w} \% \mathrm{PaHCl}$-LLC (B) studies.

Abbreviations: $\mathrm{PaHCl}$, papaverine hydrochloride; LLC, lyotropic liquid crystal. 
epidermis (Figure 3B) were studied with vertical Franz diffusion cell. In the case of the $2.5 \mathrm{w} / \mathrm{w} \% \mathrm{PaHCl}$ concentration, the membrane diffusion examinations showed the highest drug release and diffusion through the synthetic membrane in vitro, with $1,538 \pm 82 \mu \mathrm{g} / \mathrm{cm}^{2}$ being diffused over 6 hours.

The ex vivo drug penetration was lower through the human epidermis $\left(251 \pm 53 \mu \mathrm{g} / \mathrm{cm}^{2}\right.$ after 24 hours $)$ in the case of all $\mathrm{PaHCl}$ concentrations because the ex vivo studies show not only the penetration through the human epidermis, which represents not only the diffusion profile of $\mathrm{PaHCl}$ but possibly interaction with the skin and the reservoir function of the stratum corneum as well.

When comparing the different $\mathrm{PaHCl}$ concentrations of the LLC composition, the results of diffusion in vitro and penetration ex vivo were similar. Generally speaking, the degree of diffusion and penetration increases with the increase of drug concentration. In this case, the best diffusion and penetration results were found with the smallest $2.5 \%$ concentration. These reverse membrane diffusion and skin penetration results supported the results of the structural analysis as well. The LLC system having a lower $\mathrm{PaHCl}$ concentration with a lamellar structure, and lower viscosity resulted in better diffusion and penetration.

\section{Results of Raman microscopy}

The spectra of $\mathrm{PaHCl}$, the blank LLC and the three different formulations of PaHCL-LLC were recorded. In this case, the comparison of spectra was necessary, Figure 4A presents these results with the $4 \mathrm{w} / \mathrm{w} \% \mathrm{PaHCl}-\mathrm{LLC}$ formulation. This result shows that $\mathrm{PaHCl}$ characteristic peaks appear in the PaHCL-LLC formulations, which proves that the API is enclosed in the LLC system. The Raman shift of these characteristic peaks are at around 1,606, 1,509, 1,409, 1,388, 1,301, 770, 744, 713, 663, 647 and $361 \mathrm{~cm}^{-1}$. These shifts mostly denote the characteristic stretching and deformation vibrations of the $\mathrm{PaHCl}$ rings. ${ }^{28}$ These characteristic peaks and their regions are shown in Figure 4A and B, respectively.

After finding the characteristic vibrational peaks of $\mathrm{PaHCl}$ in the API-containing LLC system, the three different PaHCl-LLC formlations' spectra were compared as shown in Figure 4B. The intensities of the characteristic $\mathrm{PaHCl}$ ring deformation and stretching vibrations increase with the increasing concentration, according to Lambert-Beer's law.

After obtaining information with Raman microscopy about the $\mathrm{PaHCl}$ containing LLC systems and evidence of the successful $\mathrm{PaHCl}$ intercalation into the LLCs, evaluation of the Raman measurements of the skin penetration was performed. The correlation maps were produced, which showed the distribution of $\mathrm{PaHCl}$ by using the appropriate spectra for fitting to the treated skin spectra. As shown in Figure 4, $\mathrm{PaHCl}$ is easily determined from the LLC but the intensities of the characteristic peaks of $\mathrm{PaHCl}$ are very low. Therefore, the pure API's spectrum could not be used for making the

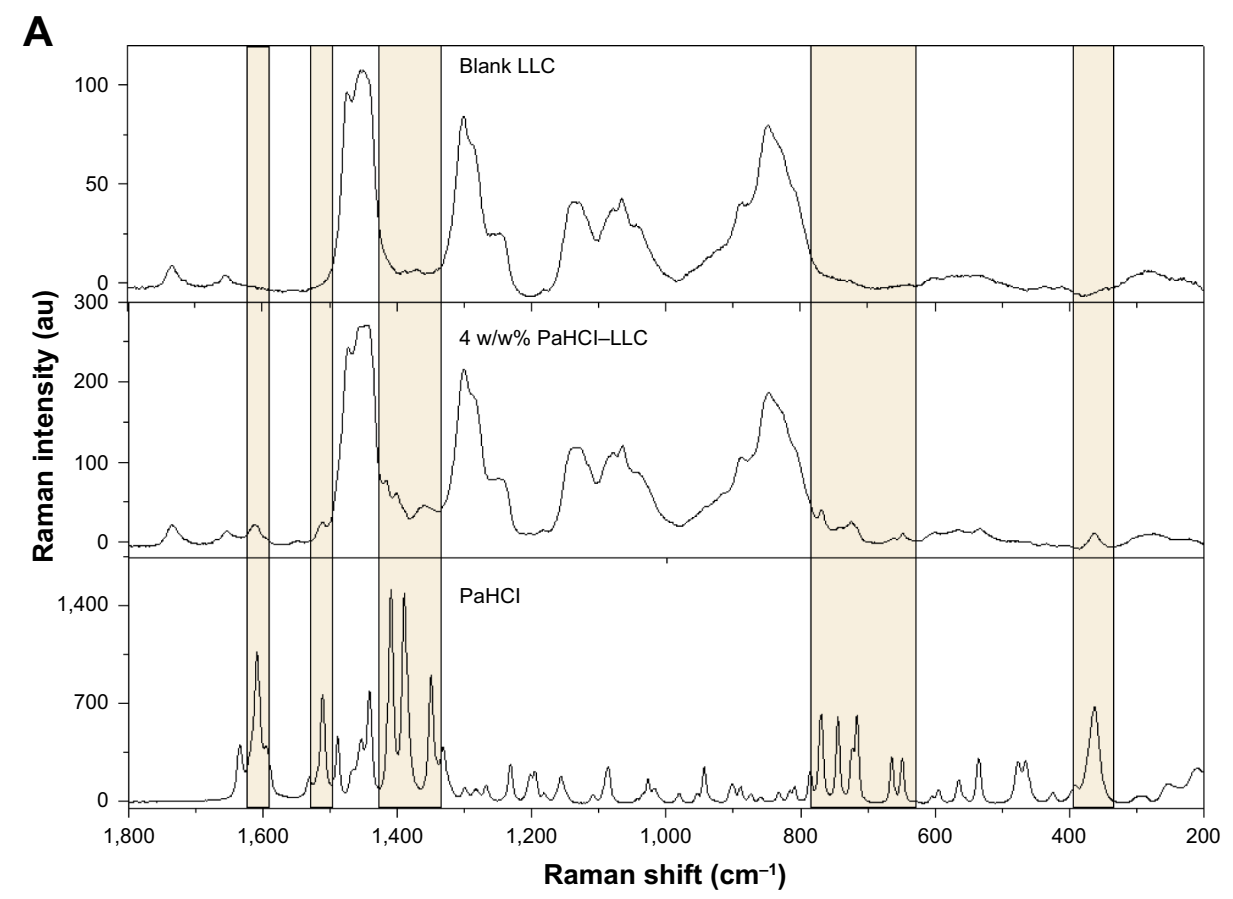

Figure 4 (Continued) 


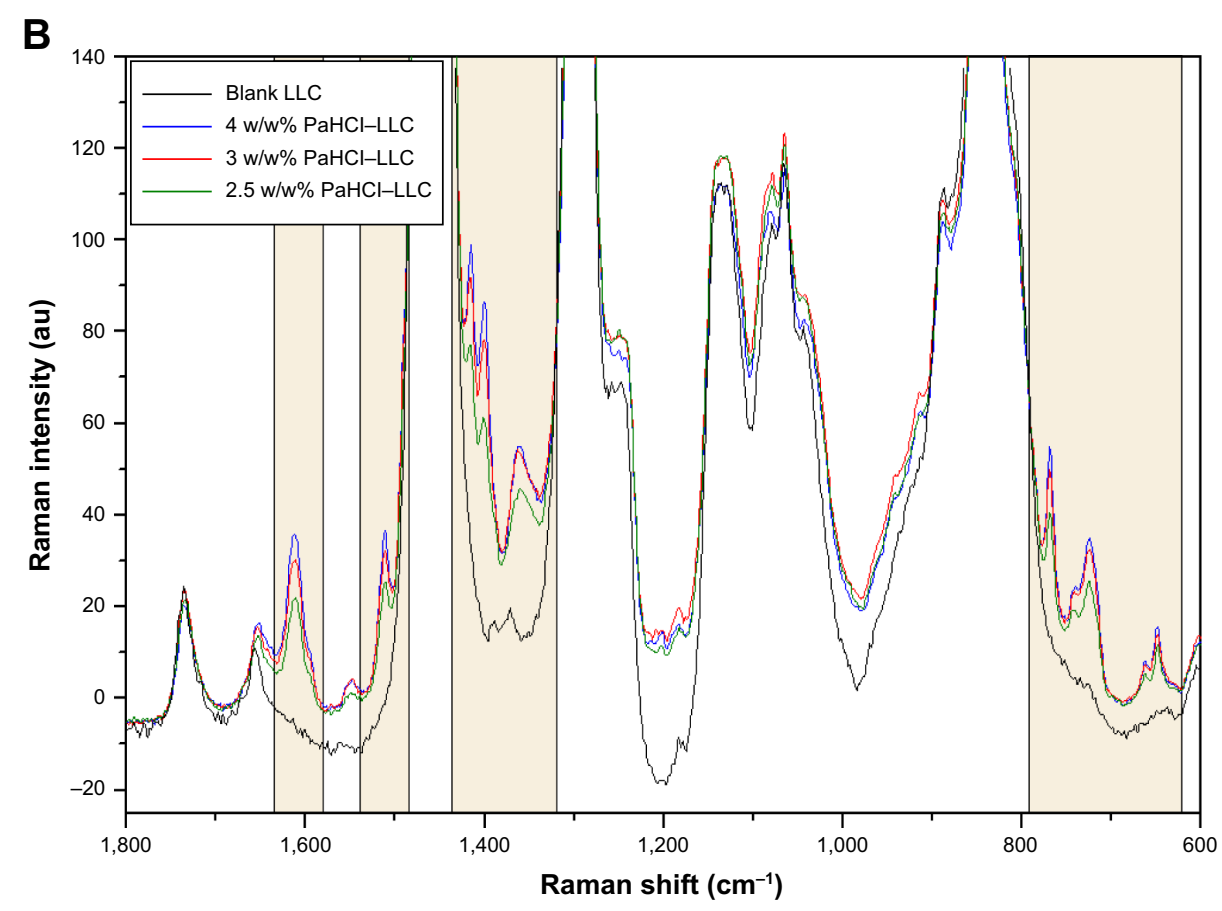

Figure 4 Comparison of $\mathrm{PaHCl}$, blank LLC and PaHCl-LLC spectra (A) and the effect of PaHCl concentration on the PaHCl-LLC spectra (B). Abbreviations: $\mathrm{PaHCl}$, papaverine hydrochloride; LLC, lyotropic liquid crystal.

acceptable correlation map. In this case, we had to assume the use of the PaHCl-LLC spectrum for making the skin distribution correlation maps, which indicates the presence of $\mathrm{PaHCl}$ as well. Thus, the correlation maps of the treated skin with three different amounts of PaHCl-containing LLCs were made by using the actual spectrum of the LLC systems. As control, a non-treated skin correlation map was evaluated. The results are shown in Figure 5.

The Raman correlation maps prove the presence of $\mathrm{PaHCl}-\mathrm{LLC}$ in the different regions of the human skin.
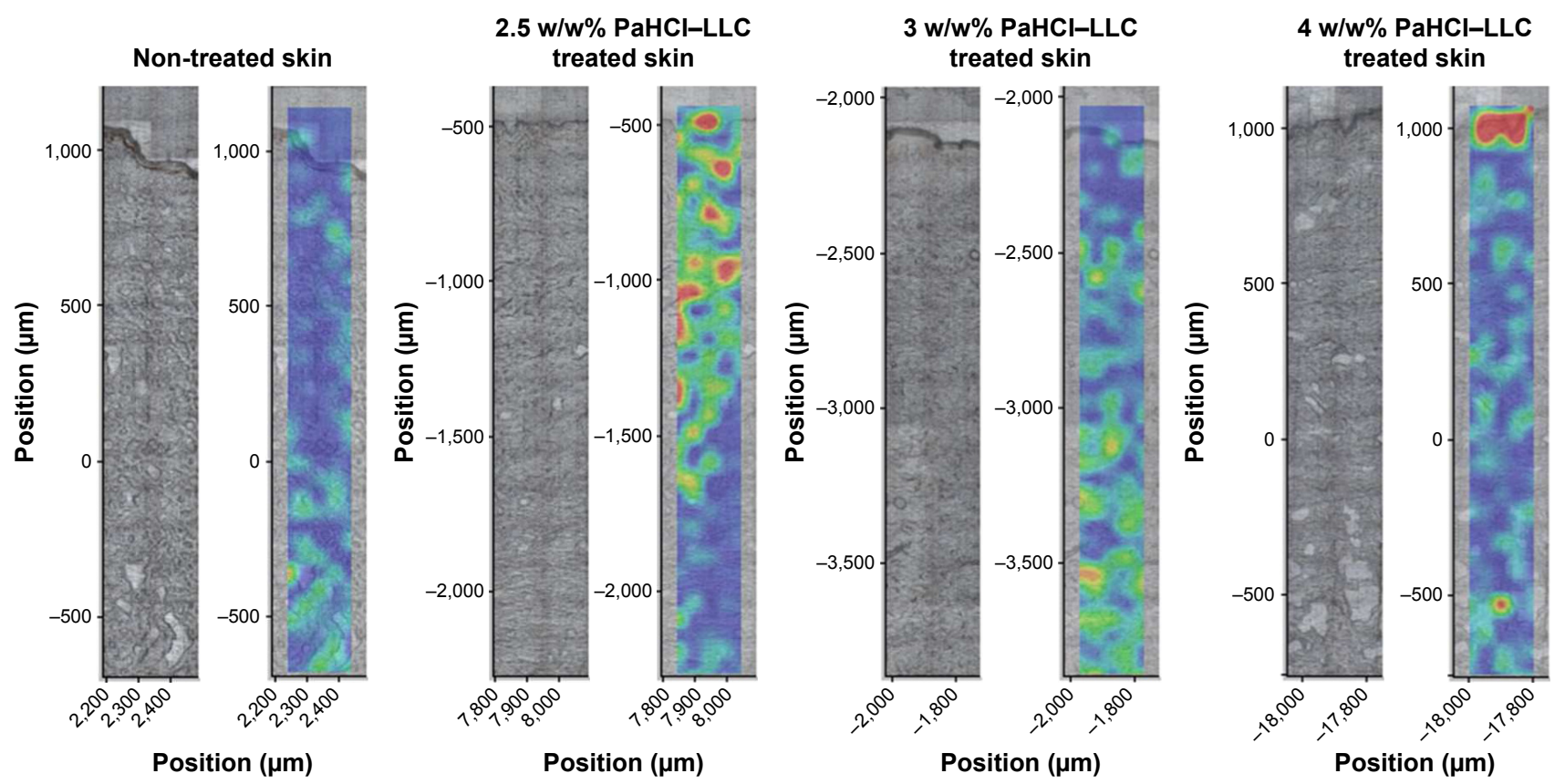

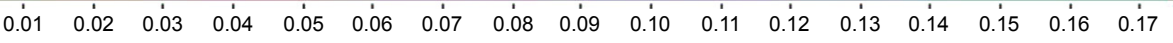

Figure 5 Raman correlation maps for the distribution of $\mathrm{PaHCl}$ of different API concentration LLCs in skin layers.

Abbreviations: $\mathrm{PaHCl}$, papaverine hydrochloride; API, active pharmaceutical ingredient; LLC, lyotropic liquid crystal. 
In correlation with the ex vivo skin penetration results (Figure 4B), the most effective penetration is shown with the $2.5 \mathrm{w} / \mathrm{w} \%$ PaHCl-containing LLC; $\mathrm{PaHCl}$ could be found in the region of the dermis and the epidermis in the skin. With increasing $\mathrm{PaHCl}$ concentration, the penetration decreases. In correlation with the rheological investigations, the less effective LLC system is the highest PaHCl-containing LLC system. Therefore, as shown in Figure 5, the whole composition could be found only in the stratum corneum region in the skin and penetration was blocked.

\section{Conclusion}

The injectable delivery of $\mathrm{PaHCl}$ is hampered by several disadvantages including priapism, pain and low patient compliance; thus, this form is excluded from therapy. In the current research, different concentrations of PaHCl-loaded LLCs were formulated to investigate the transdermal penetration of the drug. Topically used $\mathrm{PaHCl}$ incorporated in the LLC delivery system is suitable for deep skin penetration; thus, the drug can reach the cavernous bodies by exerting the effect through the underlying vessels. In this study, samples of $\mathrm{PaHCl}$ used at lower concentrations of the liquid crystalline system showed better diffusion and penetration values. Structural studies have demonstrated that the structure of the system varies with increasing drug concentration. The formula that contains $2.5 \mathrm{w} / \mathrm{w} \%$ of the API had the best characteristics. LLCs in the lamellar structure, characterized by lower concentrations, promote the diffusion of active ingredients throughout the skin. The Raman correlation maps complete the other ex vivo skin penetration measurement as a separate analysis.

Considering the average penis size, the surface on which the formulation can be used is $\sim 89.16 \mathrm{~cm}^{2}$. Based on the best formulation results, more than $3,000 \mu \mathrm{g} \mathrm{PaHCl}$ penetrated into the dermis ex vivo in 1 hour. Compared to the dose of injection that was tailored individually (dose of injection individually titrated: $2,500-37,500 \mu \mathrm{g}$ of active ingredient), our formulation may be a substitute for injection therapy.

It can be concluded that, in ex vivo circumstances, the LLC system with $2.5 \mathrm{w} / \mathrm{w} \%$ of PaHCl concentration has great potential for helping drug permeation into the dermis, and efficacy of the topical treatment for ED can be predicted. The developed formula is suitable for clinical studies to prove its efficiency in ED.

\section{Disclosure}

The author reports no conflicts of interest in this work.

\section{References}

1. Burnett AL, Nehra A, Breau RH, et al. Erectile dysfunction: AUA guideline. American Urological Association. 2005:1-288.

2. Hatzimouratidis K, Amar E, Eardley I, et al. Guidelines on Male Sexual Dysfunction. Erectile Dysfunction and Premature Ejaculation. 2010;57(5):804-814.

3. Lewis RW. Epidemiology of erectile dysfunction. Urol Clin North Am. 2001;28(2):209-216.

4. Haro JM, Beardsworth A, Casariego J, et al. Treatment-seeking behavior of erectile dysfunction patients in Europe: Results of the Erectile Dysfunction Observational Study. J Sex Med. 2006;3(3):530-540.

5. Malaysia Urological Association and MEDACT. Clinical Practice Guide in Erectile Dysfunction. 1998;13.

6. Hatzimouratidis K, Salonia A, Adaikan G, et al. Pharmacotherapy for Erectile Dysfunction: Recommendations From the Fourth International Consultation for Sexual Medicine (ICSM 2015). J Sex Med. 2016;13(4): 465-488.

7. Sakamoto T, Koga Y, Hikota M, et al. The discovery of avanafil for the treatment of erectile dysfunction: A novel pyrimidine-5-carboxamide derivative as a potent and highly selective phosphodiesterase 5 inhibitor. Bioorg Med Chem Lett. 2014;24(23):5460-5465.

8. Hilz MJ. Erectile dysfunction - diagnostic approach and treatment options. Suppl Clin Neurophysiol. 2000;53:234-236.

9. Bodner DR, Haas CA, Krueger B, Seftel AD. Intraurethral alprostadil for treatment of erectile dysfunction in patients with spinal cord injury. Urology. 1999;53(1):199-202.

10. Yap RL, Mcvary KT. Topical agents and erectile dysfunction: is there a place? Curr Urol Rep. 2002;3(6):471-476.

11. Wang AY, Podlasek CA. Role of Nanotechnology in Erectile Dysfunction Treatment. J Sex Med. 2017;14(1):36-43.

12. Gruenwald I, Appel B, Massarwa O. P-01-071 Safety and feasibility of VL\#FIA3-30- a new local topical agent for the treatment of erectile dysfunction. J Sex Med. 2017;14(4):e179.

13. Deák G, Berkó S, Ambrus R, Csányi E, Szabó-Révész P, Pajor L. C200: Examination of nanonized papaverine hydrochloride penetration through the penile skin. European Urology Supplements. 2014;13(6):e1370.

14. Owen JA, Saunders F, Harris C, et al. Topical nitroglycerin: a potential treatment for impotence. J Urol. 1989;141(3):546-548.

15. Foldvari M, Oguejiofor C, Afridi S, Kudel T, Wilson T. Liposome encapsulated prostaglandin $\mathrm{E} 1$ in erectile dysfunction: correlation between in vitro delivery through foreskin and efficacy in patients. Urology. 1998;52(5):838-843.

16. Elnaggar YS, El-Massik MA, Abdallah OY. Fabrication, appraisal, and transdermal permeation of sildenafil citrate-loaded nanostructured lipid carriers versus solid lipid nanoparticles. Int J Nanomedicine. 2011;6:3195-3205.

17. Ali MF, Salem HF, Abdelmohsen HF, Attia SK. Preparation and clinical evaluation of nano-transferosomes for treatment of erectile dysfunction. Drug Des Devel Ther. 2015;9:2431-2447.

18. Badr-Eldin SM, Ahmed OA. Optimized nano-transfersomal films for enhanced sildenafil citrate transdermal delivery: ex vivo and in vivo evaluation. Drug Des Devel Ther. 2016;10:1323-1333.

19. Fahmy UA. Nanoethosomal transdermal delivery of vardenafil for treatment of erectile dysfunction: optimization, characterization, and in vivo evaluation. Drug Des Devel Ther. 2015;9:6129-6137.

20. Steidle C, Padma-Nathan H, Salem S, et al. Topical alprostadil cream for the treatment of erectile dysfunction: a combined analysis of the phase II program. Urology. 2002;60(6):1077-1082.

21. Estracanholli EA, Praça FS, Cintra AB, Pierre MB, Lara MG. Liquid crystalline systems for transdermal delivery of celecoxib: in vitro drug release and skin permeation studies. AAPS PharmSciTech. 2014;15(6):1468-1475.

22. Fehér A. Formulation and investigation of in situ gelling lyotropic liquid crystalline systems [Ph.D. Thesis]. University of Szeged; 2006. 
23. Glina S, Virag R, Luis Rhoden E, Sharlip ID. Intracavernous Injection of Papaverine for Erectile Failure R. Virag. J Sex Med. 2010;7(4): 1331-1335.

24. Balázs B. Investigation of the skin barrier function and transdermal drug delivery techniques. PhD Thesis. Szeged: University of Szeged (2016).

25. Sütő B, Berkó S, Kozma G, et al. Development of ibuprofen-loaded nanostructured lipid carrier-based gels: characterization and investigation of in vitro and in vivo penetration through the skin. Int $J$ Nanomedicine. 2016;11:1201-1212.

26. Selivanova NM, Konov AB, Romanova KA, Gubaidullin AT, Galyametdinov YG. Lyotropic La-containing lamellar liquid crystals: phase behaviour, thermal and structural properties. Soft Matter. 2015;11(39):7809-7816.
27. Lombardo D, Kiselev MA, Magazù S, Calandra P, et al. Amphiphiles Self-Assembly: Basic Concepts and Future Perspectives of Supramolecular Approaches. Advances in Condensed Matter Physics. 2015; 2015:1-22.

28. Leopold N, Baena JR, Bolboaca M, Cozar O, Kiefer W, Lendl B. IR, and surface-enhanced Raman spectroscopy of papaverine: An automated setup for in situ synthesis of the silver substrate and recording of the SER spectraaman. Vib Spectrosc. 2004;36:47-55.

\section{Publish your work in this journal}

Drug Design, Development and Therapy is an international, peerreviewed open-access journal that spans the spectrum of drug design and development through to clinical applications. Clinical outcomes, patient safety, and programs for the development and effective, safe, and sustained use of medicines are the features of the journal, which has also been accepted for indexing on PubMed Central. The manuscript management system is completely online and includes a very quick and fair peer-review system, which is all easy to use. Visit http://www.dovepress.com/testimonials.php to read real quotes from published authors.

Submit your manuscript here: http://www.dovepress.com/drug-design-development-and-therapy-journal 